\title{
Infliximab Trough Levels and Quality of Life in Patients with Inflammatory Bowel Disease in Maintenance Therapy
}

\author{
Rogério S. Parra (D, Marley R. Feitosa, Letícia C. H. Ribeiro, Lais A. Castro, José J. R. Rocha, \\ and Omar Féres
}

Department of Surgery and Anatomy, Ribeirão Preto Medical School, University of São Paulo, Ribeirão Preto, SP, Brazil

Correspondence should be addressed to Rogério S. Parra; rsparra@hcrp.usp.br

Received 25 January 2018; Revised 4 April 2018; Accepted 12 April 2018; Published 8 May 2018

Academic Editor: Paolo Gionchetti

Copyright ( 2018 Rogério S. Parra et al. This is an open access article distributed under the Creative Commons Attribution License, which permits unrestricted use, distribution, and reproduction in any medium, provided the original work is properly cited.

\begin{abstract}
Objective. Investigate the association between infliximab trough levels and quality of life in inflammatory bowel disease patients in maintenance therapy. Methods. We carried out a transversal study with inflammatory bowel disease patients in infliximab maintenance therapy. Infliximab trough levels were determined using a quantitative rapid test. Disease activity indices (partial Mayo Score and Harvey-Bradshaw Index) and endoscopic scores (endoscopic Mayo Score or Simple Endoscopic Score in Crohn's disease) were obtained. Quality of life was assessed using the Inflammatory Bowel Disease Questionnaire (IBDQ). Results. Seventy-one consecutive subjects were included in the study (55 with Crohn's disease and 16 with ulcerative colitis). Drug levels were considered satisfactory $(\geq 3 \mu \mathrm{g} / \mathrm{mL})$ in 28 patients $(39.4 \%)$ and unsatisfactory $(<3 \mu \mathrm{g} / \mathrm{mL})$ in $43(60.6 \%)$. Satisfactory trough levels were associated with higher rates of clinical remission and mucosal healing. Higher trough levels were also associated with improved IBDQ scores, particularly regarding bowel symptoms, systemic function, and social function. Conclusion. Satisfactory trough levels of infliximab were associated with higher rates of clinical remission, mucosal healing, and improved quality of life in inflammatory bowel disease patients on maintenance therapy.
\end{abstract}

\section{Introduction}

Inflammatory bowel diseases (IBD), such as Crohn's disease (CD) and ulcerative colitis (UC), constitute a significant burden for the patients and the society [1]. Patients with CD and UC require frequent outpatient care, hospitalizations, and surgeries; some of them need stomas. The described changes cause functional impairment and great deterioration in quality of life. IBD has a chronic character and affects mostly young people. The disease can reduce the ability to work, decrease productivity, cause interruptions in employment, and have negative effects in patients' social and emotional well-being [2].

Infliximab (IFX), an antitumor necrosis factor alpha (TNF- $\alpha$ ) antibody, is a biologic drug used for the treatment of CD and UC. IFX is effective in inducing and maintaining remission in patients with CD and UC [3]. Despite its effectiveness in both induction and maintenance of remission, a substantial number of patients will eventually lose response. Loss of response ("flares") is associated with hospitalization and even surgeries, decreasing the quality of life $[4,5]$.

There is increasing evidence that clinical remission (CR) and mucosal healing $(\mathrm{MH})$ are associated with better response to treatment, less hospitalization, lower surgery rates, and, consequently, improved quality of life in patients with IBD [4-7]. IFX trough levels higher than $>2-3 \mu \mathrm{g} / \mathrm{ml}$ are associated with higher rates of sustained clinical and biochemical remission and improved endoscopic outcomes. Patients with relapse often have lower trough serum drug levels $[8,9]$.

Few studies correlated IFX trough levels with quality of life. The impact of loss of quality of life and, consequently, less social function, emotional functional, and worse symptoms, has not been investigated in detail in our country. The purpose of the present study was to investigate the 


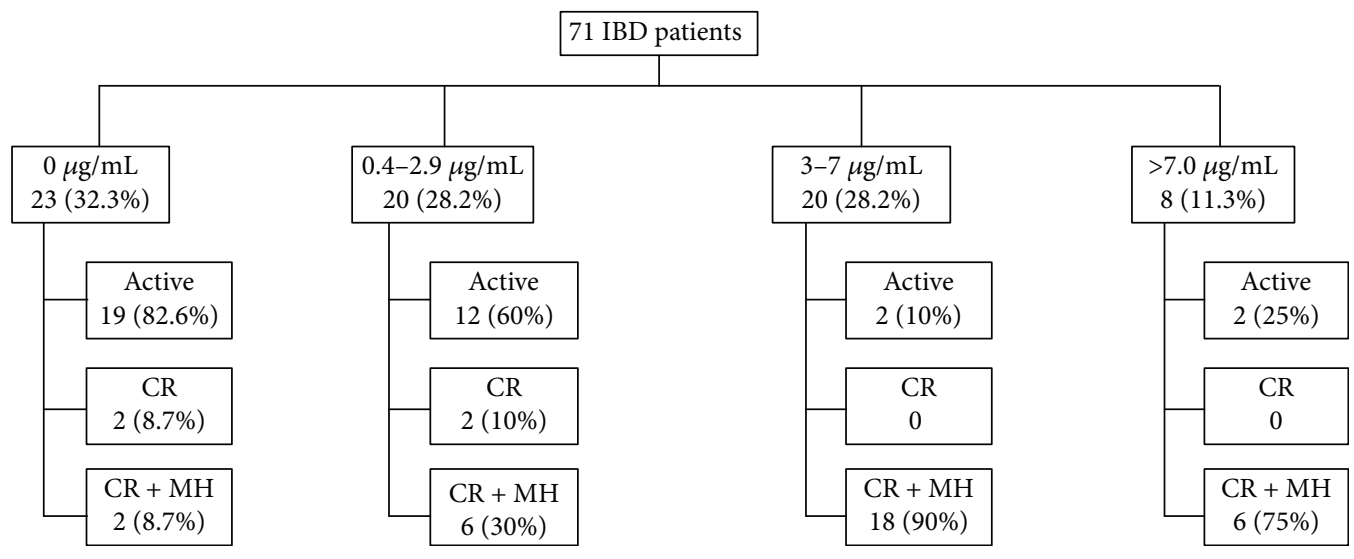

FIGURE 1: Inflammatory bowel disease (IBD) patients according IFX trough levels and comparison between clinical remission (CR) and mucosal healing.

association between IFX trough levels, response to treatment, and quality of life in a group of Brazilian IBD patients.

\section{Materials and Methods}

2.1. Study Design and Participants. A transversal study was performed in 71 consecutive patients with CD and UC on IFX maintenance therapy $(5 \mathrm{mg} / \mathrm{kg})$. All of the patients signed an informed consent statement prior to their participation, and the study was approved by the hospital's ethics committee.

2.2. Determination of Infliximab Serum Levels. IFX trough levels were obtained from blood samples collected immediately before drug infusion. Quantitative determination in serum was performed with the Quantum Blue ${ }^{\circledR}$ Infliximab assay (BÜHLMANN, Schönenbuch, Switzerland), as described elsewhere [10]. Briefly, serum samples were diluted $1: 20$ and a $70 \mu \mathrm{L}$ aliquot was loaded into the port of the test cartridge. After a $15 \mathrm{~min}$ reaction, the cartridge was read and the results were shown on the point-of-care QB reader display. According to the manufacturer, this kit has the following analytical characteristics: the limit of detection is $0.15 \mu \mathrm{g} / \mathrm{mL}$, and the lower and upper limits of quantification are $0.4 \mu \mathrm{g} / \mathrm{mL}$ and $20 \mu \mathrm{g} / \mathrm{mL}$, respectively.

2.3. Definition of Clinical Remission and Mucosa Healing. CR was assessed with Harvey Bradshaw Index (HBI) and partial Mayo Score for CD and UC, respectively. In CD, CR was defined as $\mathrm{HBI} \leq 4$. In $\mathrm{UC}, \mathrm{CR}$ was defined as partial Mayo Score $\leq 2$ (with no individual subscore $>1$ ). Elective ileocolonoscopies/sigmoidoscopies performed at least three months before and three months after blood collection were considered eligible for endoscopic evaluation. $\mathrm{MH}$ was considered Simple Endoscopic Score $\leq 2$ (in CD) or a Mayo Endoscopic Subscore $\leq 1$ (in UC). Levels of infliximab were divided into two categories: satisfactory $(\geq 3 \mu \mathrm{g} / \mathrm{mL})$ and unsatisfactory $(<3 \mu \mathrm{g} / \mathrm{mL})$ in comparison with $\mathrm{MH}, \mathrm{CR}$, and quality of life.

2.4. Questionnaires. Quality of life was measured using the Inflammatory Bowel Disease Questionnaire (IBDQ). It consists of a 32-item questionnaire of four dimensions: bowel-related symptoms (e.g., loose stools and abdominal pain), systemic function (e.g., fatigue and sleep pattern), social function (e.g., ability to attend work and social events), and emotional status (e.g., anger, depression, and irritability). The response for each question ranges from 1 (significant impairment) to 7 (no impairment) [11].

The total IBDQ ranges from 32 (very poor quality of life) to 224 (perfect quality of life). Patients in symptomatic remission usually have a score of 170 or more. The validity, reliability, and responsiveness of this questionnaire have been previously established [12].

IBDQ was correlated with $\mathrm{CR}$ and $\mathrm{MH}$ and with IFX serum levels.

2.5. Statistical Analysis. Categorical variables were expressed as frequencies/percentages and continuous variables as means \pm standard deviation. The one-sample KolmogorovSmirnov test was used to assess the normality of continuous variables. The ANOVA test was used to compare continuous variables. Fisher's exact test or $\chi^{2}$ were used to compare categorical variables. The correlation between IFX trough levels, $\mathrm{CR}, \mathrm{MH}$, and quality of life was performed through a receiver operating characteristic curve (ROC) analysis. All $p$ values were 2-sided, and a significance level of $5 \%$ was established. Statistical analysis was performed with IBM $^{\circledR}$ SPSS ${ }^{\circledR}$ Statistics 20 (IBM SPSS, Costa Mesa, CA).

\section{Results}

Seventy-one patients were included (55 with $\mathrm{CD}$ and 16 with UC) (Figure 1). Most patients were female (43/60.6\%), of Caucasian ethnicity (63/88.7\%), economically active (48/67.6), and with higher level of education (52/73.2\%). Table 1 summarizes patients' characteristics according to IFX trough levels. The two groups (satisfactory versus unsatisfactory) were homogeneous. There was no statistical difference between the groups when we compared age, gender, ethnicity, occupation, education, condition (CD versus UC), IFX duration therapy, smoking, and use of azathioprine (mono versus combo therapy). 
Table 1: Patients' main characteristics according to infliximab levels.

\begin{tabular}{|c|c|c|c|c|c|}
\hline \multirow{2}{*}{ Characteristics } & \multicolumn{2}{|c|}{$\mathrm{TL}<3 \mu \mathrm{g} / \mathrm{mL}$} & \multicolumn{2}{|c|}{$\mathrm{TL} \geq 3 \mu \mathrm{g} / \mathrm{mL}$} & \multirow{2}{*}{$p$ value } \\
\hline & $n$ & $\%$ & $n$ & $\%$ & \\
\hline \multicolumn{6}{|l|}{ Age } \\
\hline$\leq 40$ years & 29 & 61.7 & 18 & 38.3 & 0.803 \\
\hline$>40$ years & 14 & 58.3 & 10 & 41.7 & \\
\hline \multicolumn{6}{|l|}{ Gender } \\
\hline Male & 23 & 53.5 & 20 & 46.5 & 0.146 \\
\hline Female & 20 & 71.4 & 8 & 28.6 & \\
\hline \multicolumn{6}{|l|}{ Ethnicity } \\
\hline White & 36 & 57.1 & 27 & 42.9 & 0.135 \\
\hline Non-white & 7 & 87.5 & 1 & 12.5 & \\
\hline \multicolumn{6}{|l|}{ Education } \\
\hline Low & 11 & 57.9 & 8 & 42.1 & 0.790 \\
\hline High & 32 & 61.5 & 20 & 38.5 & \\
\hline \multicolumn{6}{|l|}{ Occupation } \\
\hline Unemployed & 17 & 73.9 & 6 & 26.1 & 0.128 \\
\hline Employed & 26 & 54.2 & 22 & 45.8 & \\
\hline \multicolumn{6}{|l|}{ Condition } \\
\hline Crohn's disease & 35 & 64.8 & 19 & 35.2 & 0.257 \\
\hline Ulcerative colitis & 8 & 47.1 & 9 & 52.9 & \\
\hline \multicolumn{6}{|l|}{ IFX duration } \\
\hline$\leq 2$ years & 20 & 57.1 & 15 & 42.9 & 0.631 \\
\hline$>2$ years & 23 & 63.9 & 13 & 36.1 & \\
\hline \multicolumn{6}{|l|}{ Azathioprine } \\
\hline No & 26 & 57.8 & 19 & 42.2 & 0.618 \\
\hline Yes & 17 & 65.4 & 9 & 34.6 & \\
\hline \multicolumn{6}{|l|}{ Smoking } \\
\hline No & 41 & 59.4 & 28 & 40.6 & 0.515 \\
\hline Yes & 2 & 100 & 0 & 0 & \\
\hline
\end{tabular}

Of the 71 patients included, 43 (60.5\%) have unsatisfactory IFX trough levels, 35 (49.3\%) were with active disease, 4 (5.6\%) were in CR (but not in $\mathrm{MH}$ ), and 32 (45\%) were in $\mathrm{CR}$ and $\mathrm{MH}$ (Figure 1).

Satisfactory trough level $(\geq 3 \mu \mathrm{g} / \mathrm{mL})$ was associated with $\mathrm{CR}$ and $\mathrm{MH}(p<0.001)$. Similarly, quality of life was better if IFX the trough concentration was higher than $\geq 3 \mu \mathrm{g} / \mathrm{mL}$ (Table 2).

\section{Discussion}

In this study, we showed that IBD patients with adequate serum IFX levels have higher rates of $\mathrm{CR}$ and $\mathrm{MH}$ and improved quality of life.

This is the first Brazilian study published to compare quality of life and IFX trough levels. CD and UC have a substantial negative influence on patients' reported quality of life. Patient-reported outcomes are considered an important component of the overall evaluation of treatment effects in patients with IBD $[13,14]$.
Patients without clinical improvement persistently have impaired quality of life over time. On the other hand, quality of life enhances in patients who regain CR and/or achieve $\mathrm{MH}$. It is known that about half of all IBD patients have relapse in disease activity during IFX maintenance therapy $[8,15]$. One of the reasons for loss of response, and consequently decrease in quality of life, is reduction in serum levels of IFX in maintenance therapy. Therapeutic drug monitoring (TDM) could be a useful tool in this cases, allowing physicians to act before loss of response.

TDM is not routinely implemented in our country. However, TDM has shown to improve treatment outcomes and has important economic consequences in patients with IBD $[8,15]$. Individualized therapy based on immunopharmacological evidence results in similar CR rates compared to dose intensification strategies. However, the treatment cost is higher when the physician does the "blinded" optimizations, instead of that based on the patient's IFX trough level.

The IBDQ is a validated and reproducible instrument, which can evaluate the quality of life of Brazilian inflammatory bowel disease patients. It includes 32 most frequent and important questions regarding the quality of life in IBD patients and is divided into four areas: intestinal symptoms, systemic symptoms, social aspects, and emotional aspects. This instrument provides additional information that is not evaluated by disease activity indices. Moreover, it is important to see the patient's point regarding his illness, including physical, physiological, and social performance [16-18]. Patient-reported outcomes are considered an important component of the overall evaluation of treatment effects in patients with IBD [19].

Our study showed better quality of life in patients with adequate serum levels of IFX. The patients presented improvement in the intestinal symptoms, besides improvement in the social function and systemic manifestations. Previous studies showed that the activity of CD is an important determinant of better quality of life. To our knowledge, this the first study, in our country, correlating IFX pharmacokinetics and quality of life in patients with IBD. Adequate IFX trough levels were correlated with reduction of signs and symptoms (CR and $\mathrm{MH}$ ) and consequently better quality of life.

One of the main objectives of disease management is to achieve long-term remission (deeply sustained remission) and prevention of complications, such as fistulas, hospitalizations, surgeries, and stomas, as well as to improve quality of life $[2,19,20]$. It is important to evaluate IBD not only for the symptoms but also for the patients' perspective regarding their disease. Achieving good quality of life in chronic diseases such as CD and UC is a huge challenge for physicians.

Some important study limitations should be noted. First, despite using a validated questionnaire, only one score of quality of life was used. It may be interesting to apply other questionnaires in future studies. Second, this was a transversal study, and the IBDQ was applied in a single opportunity. It would be important to evaluate the patient's quality of life over time. Third, we did not correlate IFX trough levels with proinflammatory biomarkers (such as CRP and faecal calprotectin) as well with the patient's body mass index (BMI). 
TABLE 2: Clinical remission, mucosal healing, and quality of life scores according to infliximab levels.

\begin{tabular}{|c|c|c|c|c|c|}
\hline \multirow{2}{*}{ Disease control } & \multicolumn{2}{|c|}{$\mathrm{TL} \geq 3 \mu \mathrm{g} / \mathrm{mL}$} & \multicolumn{2}{|c|}{$\mathrm{TL}<3 \mu \mathrm{g} / \mathrm{mL}$} & \multirow{2}{*}{$p$ value } \\
\hline & $n$ & $\%$ & $n$ & $\%$ & \\
\hline Clinical remission & 24 & 85.7 & 12 & 27.9 & $<0.001$ \\
\hline Mucosal healing & 24 & 85.7 & 8 & 18.6 & $<0.001$ \\
\hline Quality-of-life score & Mean & $\pm \mathrm{SD}$ & Mean & $\pm \mathrm{SD}$ & \\
\hline Bowel symptoms $($ maximum $=70)$ & 59.6 & 9.3 & 52.3 & 8.5 & 0.001 \\
\hline Systemic function $($ maximum $=35)$ & 27.3 & 5.6 & 22.7 & 5.2 & 0.001 \\
\hline Social function $($ maximum $=35)$ & 30.8 & 5.7 & 26.7 & 7.4 & 0.015 \\
\hline Emotional status $($ maximum $=84)$ & 65.1 & 16.5 & 60.0 & 12.9 & 0.148 \\
\hline Global $($ maximum $=224)$ & 183.0 & 32.6 & 161.9 & 28.9 & 0.006 \\
\hline
\end{tabular}

Factors such as BMI and proinflammatory biomarkers may influence IFX trough levels. Our intention is to conduct a prospective study to increase the casuistry and correlate all these parameters. Finally, endoscopic evaluation was not accessed in all patients.

\section{Conclusions}

Adequate IFX trough levels were associated with significantly higher rates of $\mathrm{CR}, \mathrm{MH}$, and quality of life in patients with IBD. Achieving quality of life in patients with IBD is a huge challenge for physicians. IBD symptoms have a major impact on patients' lives. TDM can be a useful and important tool in patients losing response. Further prospective studies are needed to confirm our results.

\section{Abbreviations}

IFX: Infliximab

IBD: Inflammatory bowel disease

UC: Ulcerative colitis

CD: Crohn's disease

CRP: C-reactive protein

CR: Clinical remission

MH: Mucosal healing

TDM: Therapeutic drug monitoring

IBDQ: Inflammatory bowel disease questionnaire

HBI: Harvey Bradshaw Index

TNF- $\alpha$ : Antitumor necrosis factor alpha.

\section{Data Availability}

Data were collected by the computerized hospital system and medical records. All data used and analyzed during the current study can be sent, if necessary, as e-mail request (corresponding author). All data analyzed during this study are included in this published article.

\section{Ethical Approval}

The study was approved by the hospital's ethics committee.

\section{Consent}

All of the patients signed an informed consent statement prior to their participation.

\section{Disclosure}

This manuscript was presented before as poster as follows: Feitosa MR, Parra RS, Feres O and Rocha JRR. May 2017, Vol. 85, Issue 5, Suppl, Page AB262 DOI: https://doi.org/10. 1016/j.gie.2017.03.593. Parra RS, Feitosa MR, Feres O and Ribeiro da Rocha JR. Journal of Crohn's and Colitis, Volume 11, Issue suppl_1, 1 February 2017, Pages S292 DOI: https:// doi.org/10.1093/ecco-jcc/jjx002.549.

\section{Conflicts of Interest}

The authors declare that they have no competing interests.

\section{Authors' Contributions}

Rogério S. Parra conceived and designed the study, acquired the data, and wrote and reviewed the manuscript. Marley R. Feitosa acquired the data, did the statistical analysis, and reviewed the manuscript. Letícia $\mathrm{C}$. $\mathrm{H}$. Ribeiro acquired the data. Lais A. Castro acquired the data. José J. R. Rocha and Omar Féres were responsible for the critical revising and final approval of the version to be published.

\section{Funding}

Quantum Blue Infliximab assay was donated by BÜHLMANN Laboratories AG.

\section{Acknowledgments}

The authors thank Mrs. Graziela Volpe (BÜHLMANN Laboratories AG) and Dr. Fernando Pinto (M.D., Padrão Laboratory) for sample storage and serum analysis.

\section{Supplementary Materials}

ROC curves for (A) clinical remission and (B) mucosal healing according to infliximab trough levels. (Supplementary Materials) 


\section{References}

[1] P. Jacobs, R. Bissonnette, and L. C. Guenther, "Socioeconomic burden of immune-mediated inflammatory diseases - focusing on work productivity and disability," The Journal of Rheumatology Supplement, vol. 88, pp. 55-61, 2011.

[2] P. Holko, P. Kawalec, M. Mossakowska, and A. Pilc, "Healthrelated quality of life impairment and indirect cost of Crohn's disease: a self-report study in Poland," PLoS One, vol. 11, no. 12, article e0168586, 2016.

[3] A. Armuzzi, G. van Assche, W. Reinisch et al., "Results of the 2nd scientific workshop of the ECCO (IV): therapeutic strategies to enhance intestinal healing in inflammatory bowel disease," Journal of Crohn's and Colitis, vol. 6, no. 4, pp. 492-502, 2012.

[4] J. F. Colombel, P. Rutgeerts, W. Reinisch et al., "Early mucosal healing with infliximab is associated with improved longterm clinical outcomes in ulcerative colitis," Gastroenterology, vol. 141, no. 4, pp. 1194-1201, 2011.

[5] W. Reinisch, J.-F. Colombel, W. J. Sandborn et al., "Factors associated with short- and long-term outcomes of therapy for Crohn's disease," Clinical Gastroenterology and Hepatology, vol. 13, no. 3, pp. 539-547.e2, 2015.

[6] R. S. Parra, M. R. Feitosa, J. J. Rocha, and O. Feres, "Inflammatory bowel diseases \& disorders higher trough concentrations of infliximab are associated with clinical remission and mucosal healing in patients with inflammatory bowel disease," Journal of Inflammatory Bowel Diseases \& Disorders, vol. 1, p. 104, 2016.

[7] F. Beigel, M. Deml, F. Schnitzler et al., "Rate and predictors of mucosal healing in patients with inflammatory bowel disease treated with anti-TNF-alpha antibodies," PLoS One, vol. 9, no. 6, article e99293, 2014.

[8] N. Vande Casteele, M. Ferrante, G. van Assche et al., "Trough concentrations of infliximab guide dosing for patients with inflammatory bowel disease," Gastroenterology, vol. 148, no. 7, pp. 1320-1329.e3, 2015.

[9] C. Moore, G. Corbett, and A. C. Moss, "Systematic review and meta-analysis: serum infliximab levels during maintenance therapy and outcomes in inflammatory bowel disease," Journal of Crohn's and Colitis, vol. 10, no. 5, pp. 619-625, 2016.

[10] J. Afonso, S. Lopes, R. Gonçalves et al., "Proactive therapeutic drug monitoring of infliximab: a comparative study of a new point-of-care quantitative test with two established ELISA assays," Alimentary Pharmacology and Therapeutics, vol. 44, no. 7, pp. 684-692, 2016.

[11] G. Guyatt, A. Mitchell, E. J. Irvine et al., "A new measure of health status for clinical trials in inflammatory bowel disease," Gastroenterology, vol. 96, no. 2, pp. 804-810, 1989.

[12] E. J. Irvine, B. Feagan, J. Rochon et al., "Quality of life: a valid and reliable measure of therapeutic efficacy in the treatment of inflammatory bowel disease," Gastroenterology, vol. 106, no. 2, pp. 287-296, 1994.

[13] E. J. Irvine, Q. Zhou, and A. K. Thompson, "The Short Inflammatory Bowel Disease Questionnaire: a quality of life instrument for community physicians managing inflammatory bowel disease," American Journal of Gastroenterology, vol. 91, no. 8, pp. 1571-1578, 1996.

[14] M. C. Reilly, L. Gerlier, Y. Brabant, and M. Brown, "Validity, reliability, and responsiveness of the work productivity and activity impairment questionnaire in Crohn's disease," Clinical Therapeutics, vol. 30, no. 2, pp. 393-404, 2008.
[15] C. Steenholdt, J. Brynskov, O. Ø. Thomsen et al., "Individualised therapy is more cost-effective than dose intensification in patients with Crohn's disease who lose response to antiTNF treatment: a randomised, controlled trial," Gut, vol. 63, no. 6, pp. 919-927, 2014.

[16] R. M. A. Pontes, S. J. Miszputen, O. F. Ferreira-Filho, C. Miranda, and M. B. Ferraz, "Quality of life in patients with inflammatory bowel diseases: translation to Portuguese language and validation of the "Inflammatory Bowel Disease Questionnaire" (IBDQ)," Arquivos de Gastroenterologia, vol. 41, no. 2, pp. 137-143, 2004.

[17] M. van der Have, K. S. van der Aalst, A. A. Kaptein et al., "Determinants of health-related quality of life in Crohn's disease: a systematic review and meta-analysis," Journal of Crohn's and Colitis, vol. 8, no. 2, pp. 93-106, 2014.

[18] R. Khanna, G. Zou, G. D'Haens et al., “A retrospective analysis: the development of patient reported outcome measures for the assessment of Crohn's disease activity," Alimentary Pharmacology and Therapeutics, vol. 41, no. 1, pp. 77-86, 2015.

[19] C. Steenholdt, J. Brynskov, O. Ø. Thomsen et al., "Implications of infliximab treatment failure and influence of personalized treatment on patient-reported health-related quality of life and productivity outcomes in Crohn's disease," Journal of Crohn's and Colitis, vol. 9, no. 11, pp. 1032-1042, 2015.

[20] J. Y. Yoon, J. E. Shin, S. H. Park, D. I. Park, and J. M. Cha, “Disability due to Inflammatory Bowel Disease Is Correlated with Drug Compliance, Disease Activity, and Quality of Life," Gut and Liver, vol. 11, no. 3, pp. 370-376, 2017. 


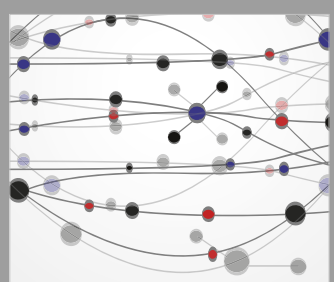

The Scientific World Journal
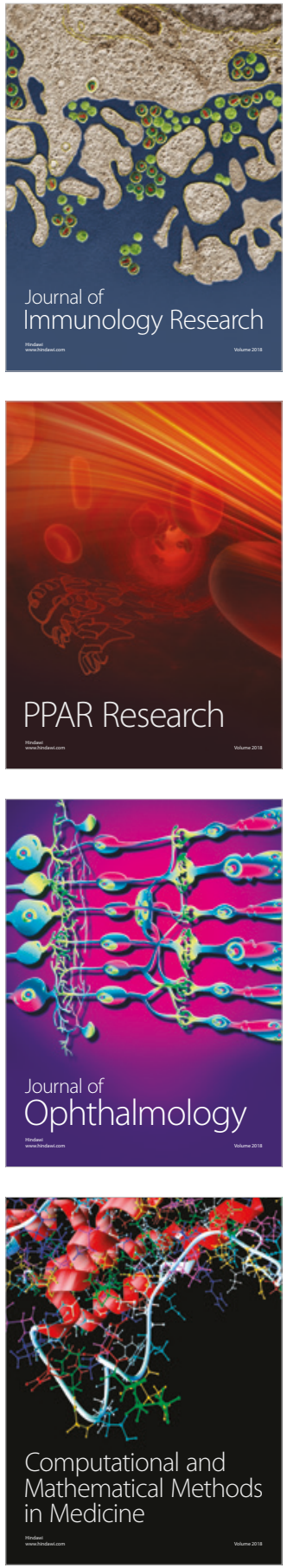

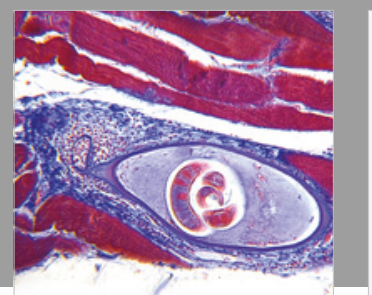

Gastroenterology Research and Practice

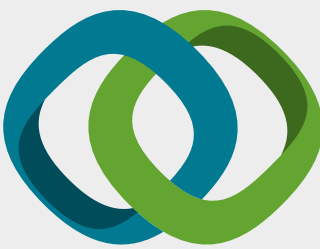

\section{Hindawi}

Submit your manuscripts at

www.hindawi.com
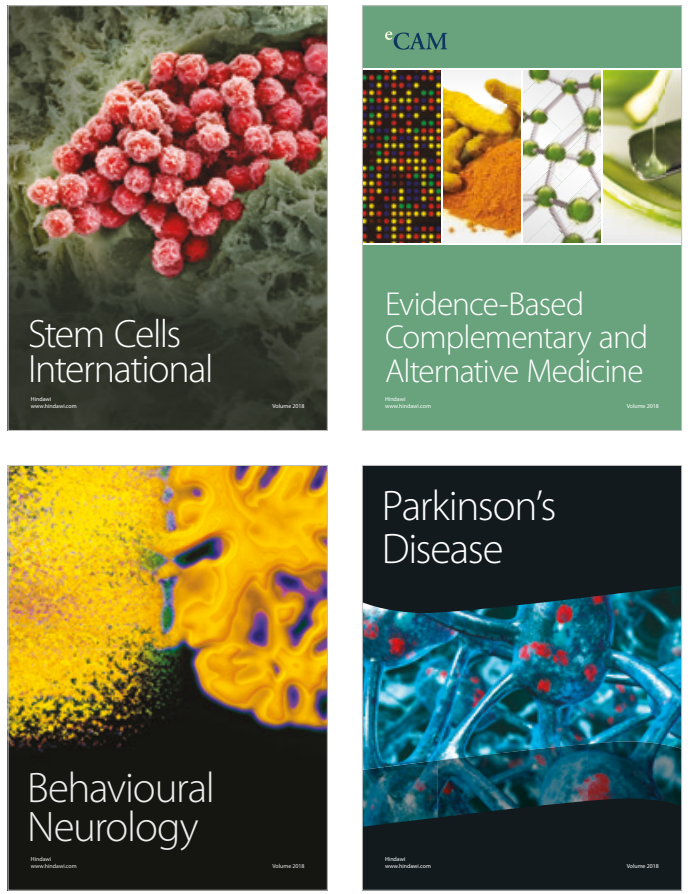

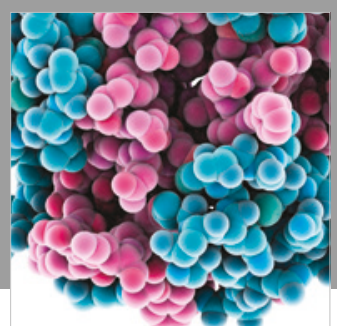

ournal of

Diabetes Research

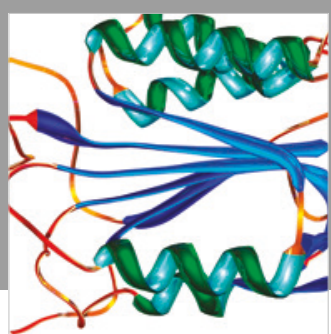

Disease Markers
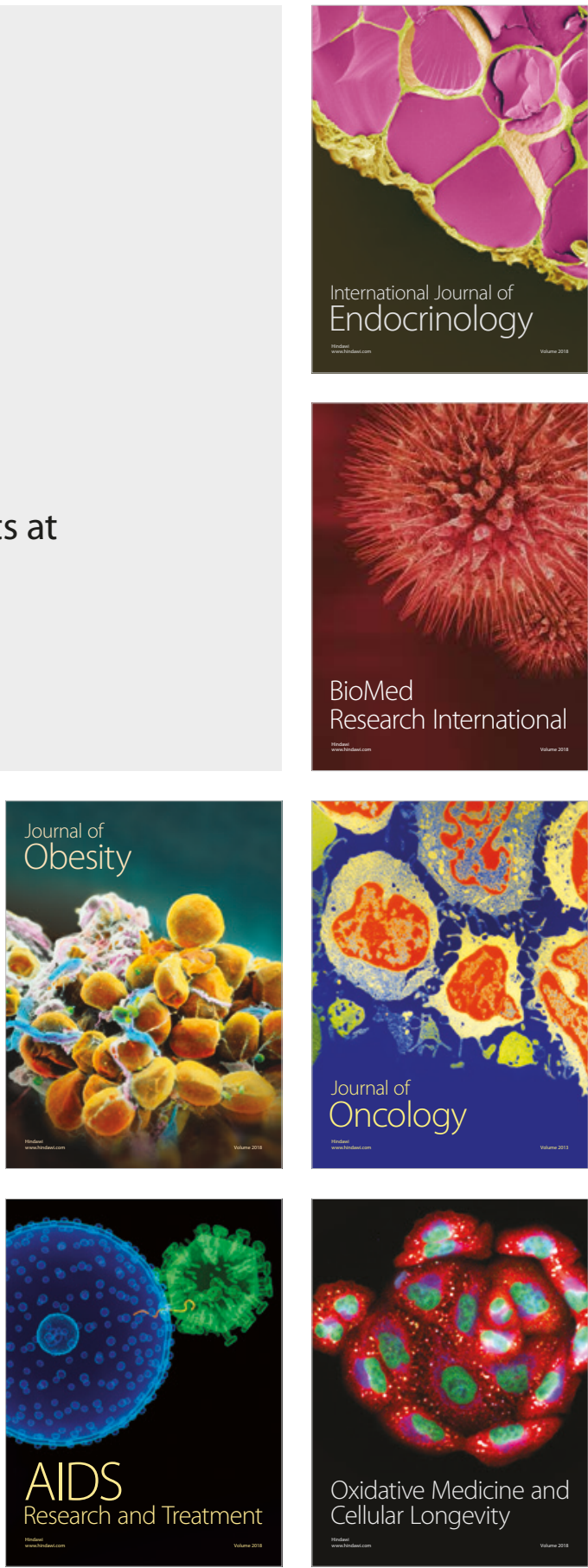